\title{
Radiation-Induced Graft Polymerization of Vinyl Monomers with Anion Groups onto MWNT Supports and Their Application as Electrogenerated Chemiluminescence (ECL) Biosensors
}

\author{
Ji-Hye Park, Yun Ok Kang, and Seong-Ho Choi \\ Department of Chemistry, Hannam University, Daejeon 305-811, Republic of Korea \\ Correspondence should be addressed to Seong-Ho Choi; shchoi@hnu.kr
}

Received 23 October 2013; Accepted 13 February 2014; Published 30 March 2014

Academic Editor: Chih-Hung Hsiao

Copyright (c) 2014 Ji-Hye Park et al. This is an open access article distributed under the Creative Commons Attribution License, which permits unrestricted use, distribution, and reproduction in any medium, provided the original work is properly cited.

\begin{abstract}
Vinyl polymer-grafted multiwalled carbon nanotube (MWNT) supports with anion groups were prepared for use as biosensor supports by radiation-induced graft polymerization (RIGP) of the vinyl monomers acryloyl diphosphoric acid (ADPA), acrylic acid (AA), sodium styrenesulfonate (NaSS), and methacrylic acid (MA) onto the surface of MWNTs. The electrogenerated chemiluminescence sensors based on a glass carbon electrode (ECL-GCE) and a screen printed electrode (ECL-SPE) were fabricated by immobilization of $\mathrm{Ru}(\mathrm{bpy})_{3}{ }^{2+}$ complex after coating of vinyl polymer-grafted MWNT inks on the surface of the GCE and SPE without any polymer binders in order to obtain high electrogenerated chemiluminescence intensity. For detection of alcohol concentration, alcohol dehydrogenase $(\mathrm{ADH})$ was immobilized onto an ECL-GCE sensor prepared by poly(NaSS)-g-MWNT supports. The prepared biosensor based on $\mathrm{ADH}$ is suitable for the detection of ethanol concentration in commercial drinks.
\end{abstract}

\section{Introduction}

Radiation-induced graft polymerization can convert functional polymers on polymer substrates with specific thermal, mechanical, electronic, or crystalline properties. It has been used for the introduction of specific functional groups from various vinyl monomers to carbon materials in order to prepare supports with specific functionality for biosensors [1-4]. Free radicals generated during $\gamma$-ray irradiation of the reaction mixture are important in this type of polymerization.

Furthermore, ECL can provide highly sensitive and selective identification of species as optical signals, which are induced by specific electrochemical reactions $[5,6]$. It has been used in several bioanalytical fields and has been commercialized for the detection of clinically important analyses such as in immunoassays and DNA analysis by labeling biological molecules with ECL-active species [7].

ECL biosensors have been fabricated through the immobilization of ruthenium complexes ( $\mathrm{Ru}(\mathrm{bpy})_{3}{ }^{2+}$ ) on conducting polymer- $\mathrm{SiO}_{2}$-Nafion composite films on GC electrodes $[8,9]$. Conducting polymer- $\mathrm{SiO}_{2}$ nanocomposites have been prepared by coating polyaniline, polypyrrole, and polythiophene onto the surfaces of $\mathrm{SiO}_{2}$ nanospheres. ECL sensors have also been prepared through the immobilization of $\mathrm{Ru}(\mathrm{bpy})_{3}{ }^{2+}$ on conducting polymer-wrapped MWNTNafion composite film, $\mathrm{COOH}$-functionalized MWNTs, and $\mathrm{Au}$ nanoparticles; however, despite performing well, these sensors relied on coating the MWNTs, $\mathrm{SiO}_{2}$ nanaospheres, and $\mathrm{Au}$ nanoparticles with polymer binder to immobilize the $\mathrm{Ru}$ complex onto the GC electrode surfaces, which can decrease ECL intensity and reproducibility. Composite films prepared using polymer binder often separate from the electrode's surface during electrochemical testing.

In order to decrease the separation of polymer binder from the electrode surface, poly(GMA)-g-MWNTs were prepared by RIGP of glycidyl methacrylate (GMA) onto the surface of the MWNTs in aqueous solution. Subsequently, TEDA-modified MWNT electrodes were fabricated by hand casting after amination of the epoxy group-contained poly(GMA) using TEDA. Finally, ECL sensors were prepared by immobilization of the $\mathrm{Ru}(\mathrm{bpy})_{3}{ }^{2+}$ complex onto the TEDA-modified MWNT electrode [10]. The results of this report show that the grafted poly(GMA) chain can act as a polymer binder and the unpaired electron of the immobilized 


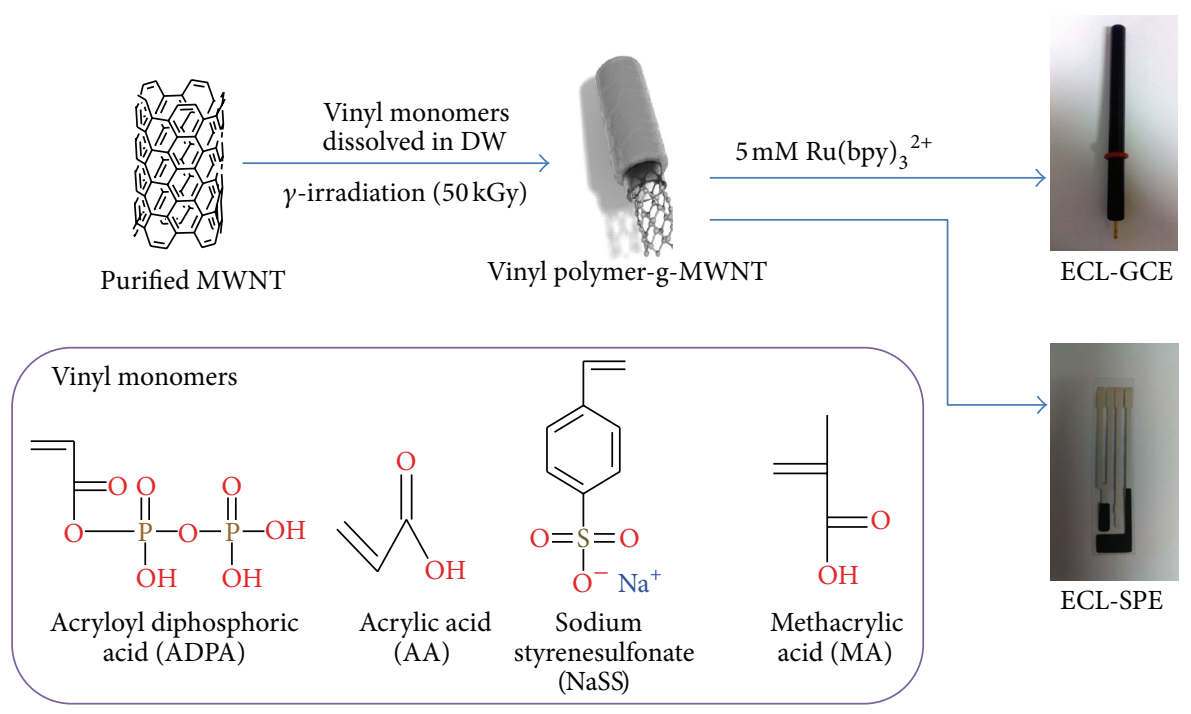

Figure 1: Preparation overview of the ECL-GCE and ECL-SPE based on vinyl polymer-g-MWNT.

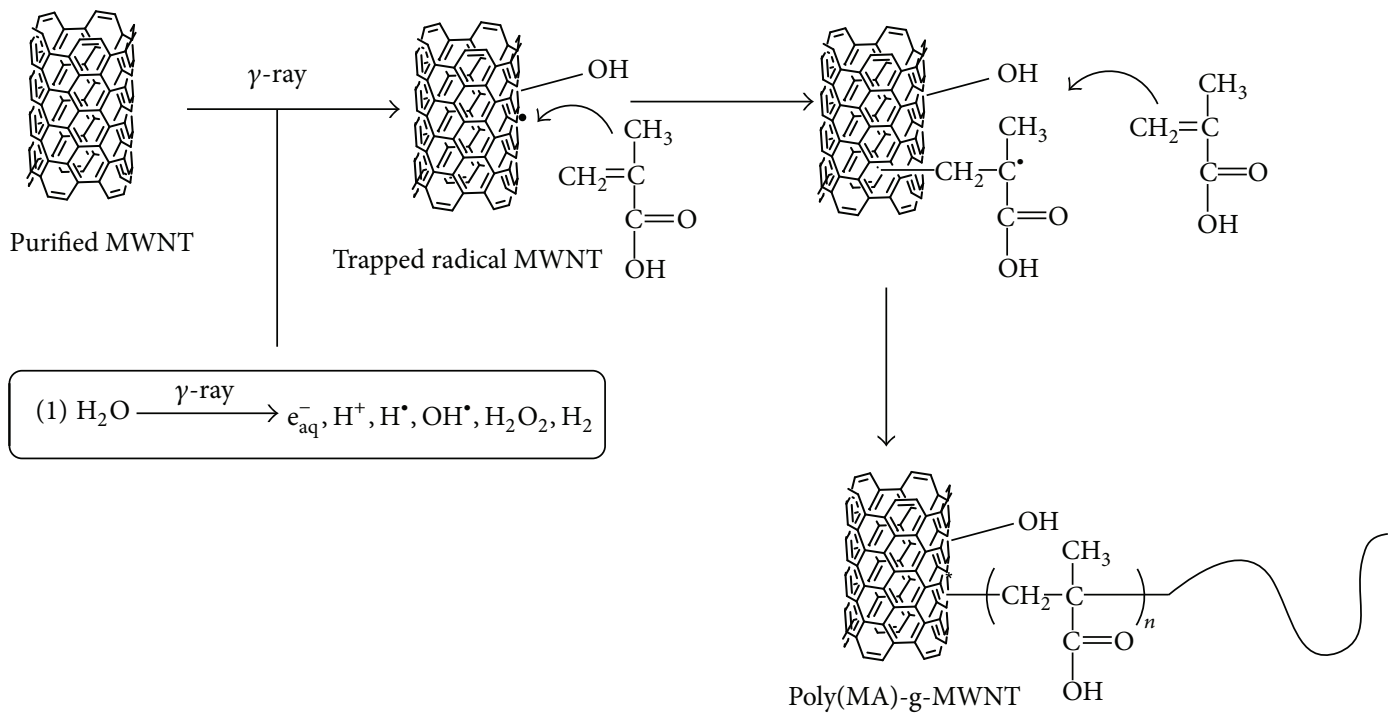

FIGURE 2: Possible grafting mechanism of the MA onto the surface of MWNT in $\mathrm{H}_{2} \mathrm{O}$ during $\gamma$-irradiation.

TEDA can interact with the $\mathrm{Ru}(\mathrm{bpy})_{3}{ }^{2+}$ complex; however, there have been only few reports on the reversal of the grafted vinyl polymers as polymer binder on electrochemical testing and no studies on the interaction effects of the anion groups with the $\mathrm{Ru}(\mathrm{bpy})_{3}{ }^{2+}$ complex in the electrochemical reaction.

In this study, we selected vinyl monomers with anion groups in order to induce radiation-induced graft polymerization onto the surface of MWNTs during $\gamma$-ray irradiation in aqueous solution at room temperature. The vinyl monomers used were acryloyl diphosphoric acid (ADPA), acrylic acid (AA), sodium styrenesulfonate (NaSS), and methacrylic acid (MA). Subsequently, ECL sensors based on glass carbon electrodes (ECL-GCE) and screen printed electrodes (ECL-SPE) were fabricated by immobilization of the $\mathrm{Ru}$ (bpy) ${ }_{3}{ }^{2+}$ complex after coating of vinyl polymer-grafted MWNT inks on the surface of the glass carbon electrodes
(GCE) and screen printed electrodes (SPE). Finally, ECL biosensors for the determination of ethanol concentration were fabricated by immobilization of alcohol dehydrogenase $(\mathrm{ADH})$ onto the prepared ECL-GCE based on poly(NaSS)-gMWNT supports.

\section{Experimental}

2.1. Reagents. Alcohol dehydrogenase (ADH, from baker's yeast, $451 \mathrm{U} / \mathrm{mg}$ solid), nicotinamide adenine dinucleotide $\left(\mathrm{NAD}^{+}\right)$, tripropylamine (TPA, 99\%), sodium 4-styrenesulfonate (NaSS), acrylic acid (AA), methacrylic acid (MA), and $\operatorname{tris}\left(2,2^{\prime}\right.$-bipyridyl)dichlororuthenium(II) $\left(\mathrm{Ru}(\mathrm{bpy})_{3}{ }^{2+}, 98 \%\right)$ were obtained from Sigma-Aldrich, Korea. MWNTs (95\%; length, $10 \mu \mathrm{m}$ ) were obtained from Hanwha Nanotech Co., Ltd., Korea. All other chemicals were of analytical grade. 


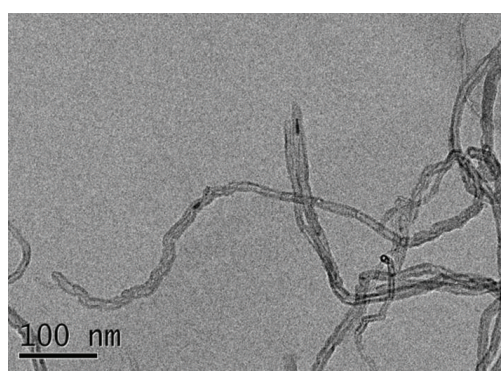

(a)

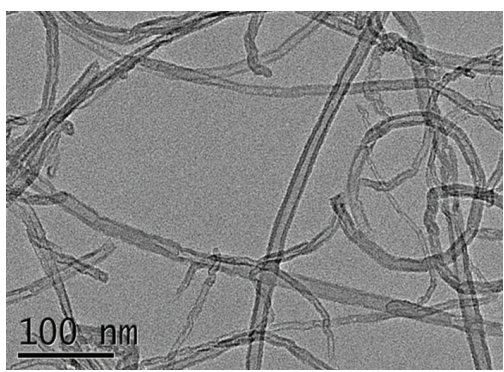

(d)

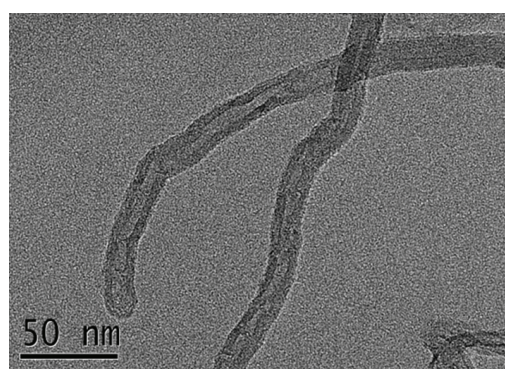

(b)

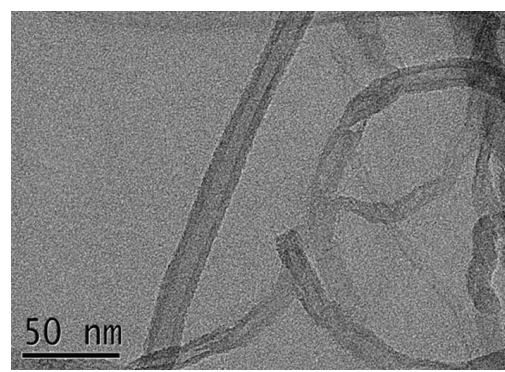

(e)

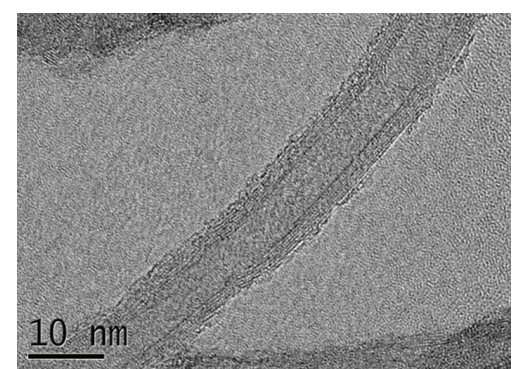

(c)

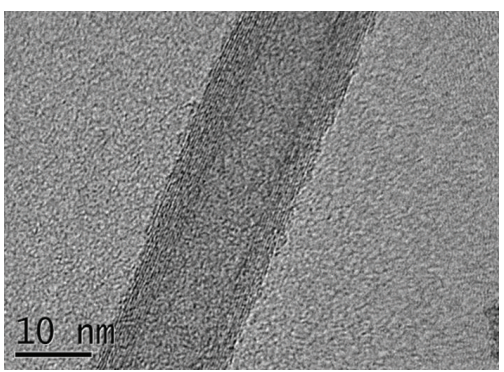

(f)

FIGURE 3: TEM images of purified MWNT (a), poly(ADPA)-g-MWNT ((b) and (c)), and poly(MA)-g-MWNT ((d), (e), and (f)).

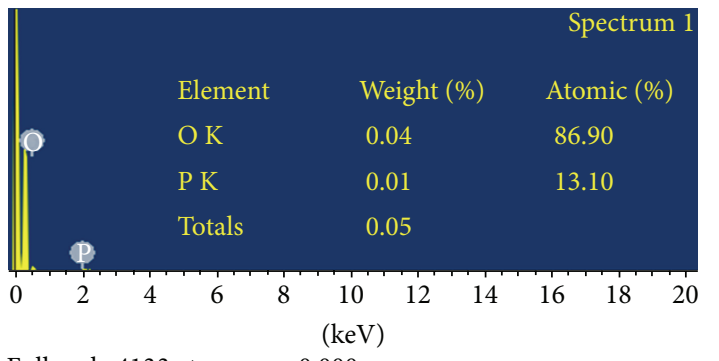

Full scale 4133 cts cursor: 0.000

(a)

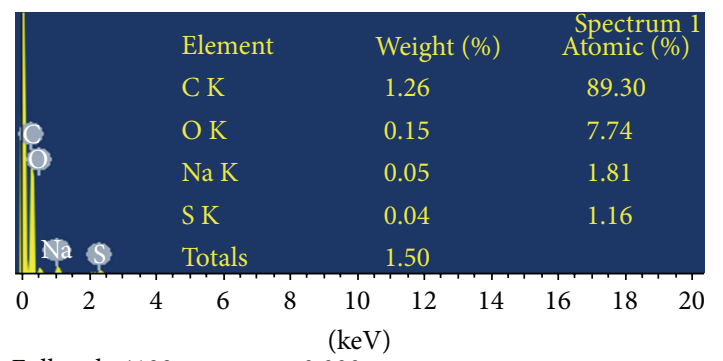

Full scale 4133 cts cursor: 0.000

(c)

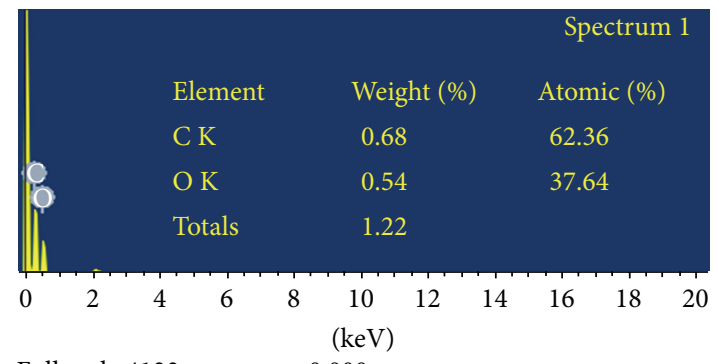

Full scale 4133 cts cursor: 0.000

(b)

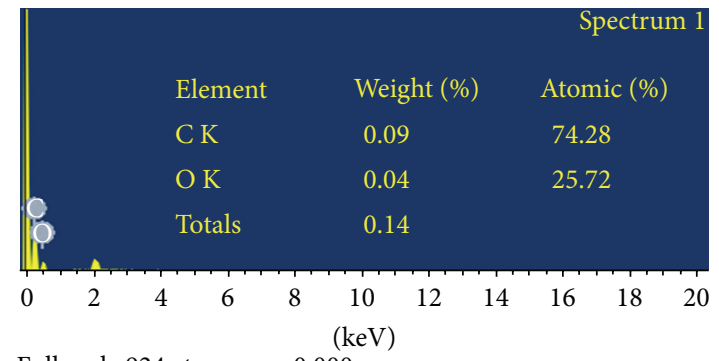

Full scale 924 cts cursor: 0.000

(d)

Figure 4: EDS data of the poly(ADPA)-g-MWNT (a), poly(AA)-g-MWNT(b), poly(NaSS)-g-MWNT (c), and poly(MA)-g-MWNT (d).

Water was purified using a Millipore purification system (Millipore, MA, USA).

2.2. Synthesis of Acryloyl Diphosphoric Acid (ADPA). ADPA was synthesized in accordance with a previous paper [10]. In detail, diphosphoric acid $(0.562 \mathrm{~mol})$ was dried under reduced pressure for $12 \mathrm{hrs}$ and then dissolved in tetrahydrofuran (THF, $210 \mathrm{~mL})$. TEA $(80 \mathrm{~mL})$ was added to the diphosphoric acid solution and the reaction mixture was stirred for $20 \mathrm{~min}$. Acryloyl chloride $(0.468 \mathrm{~mol})$ in THF $(40 \mathrm{~mL})$ was added drop by drop to the reaction mixture over $3 \mathrm{hrs}$, while the temperature was maintained at $0^{\circ} \mathrm{C}$. The reaction mixture was then stirred for $3 \mathrm{hrs}$ at room temperature. The ADPA monomer was obtained after evaporation of the solvent. The chemical structure of the ADP monomer 


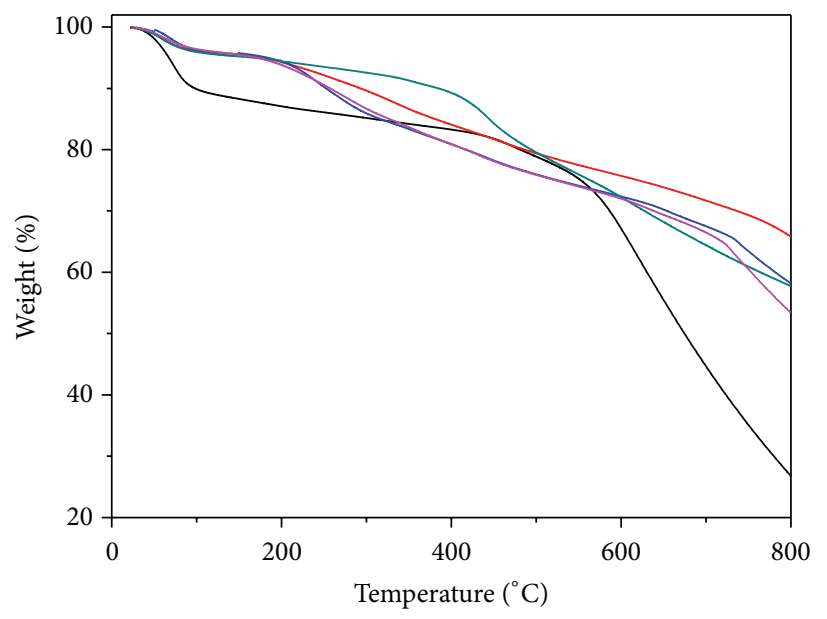

$\begin{aligned} \text { (a) } & - \text { (d) } \\ \text { (b) } & \text { (c) }\end{aligned}$

FiguRE 5: TGA curves of purified MWNT (a), the poly(ADPA)-g-MWNT (b), poly-g-MWNT (c), poly(NaSS)-g-MWNT (d), and poly (MA)g-MWNT (e).

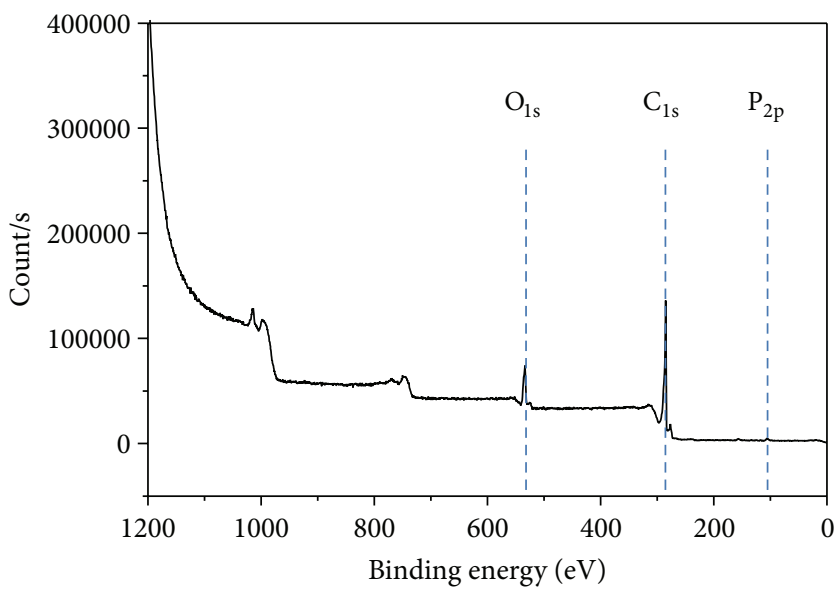

(a)

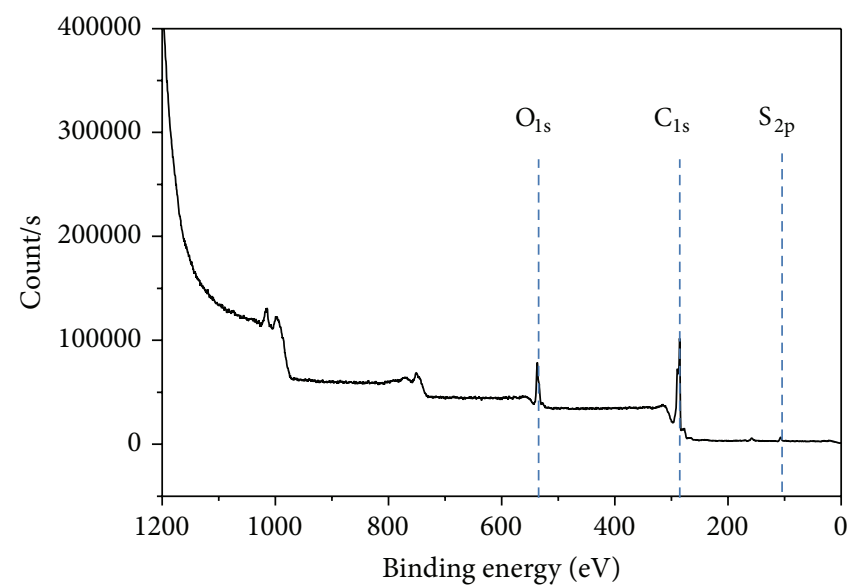

(c)

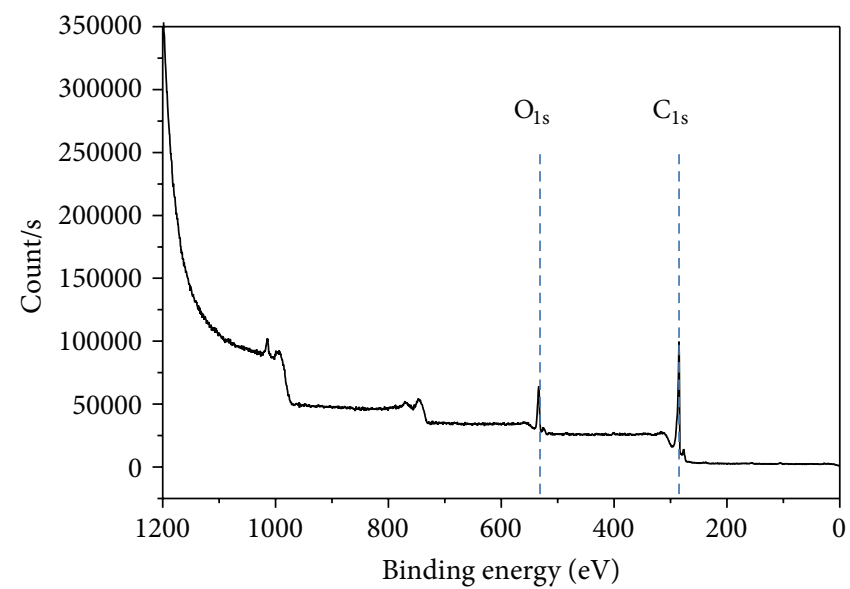

(b)

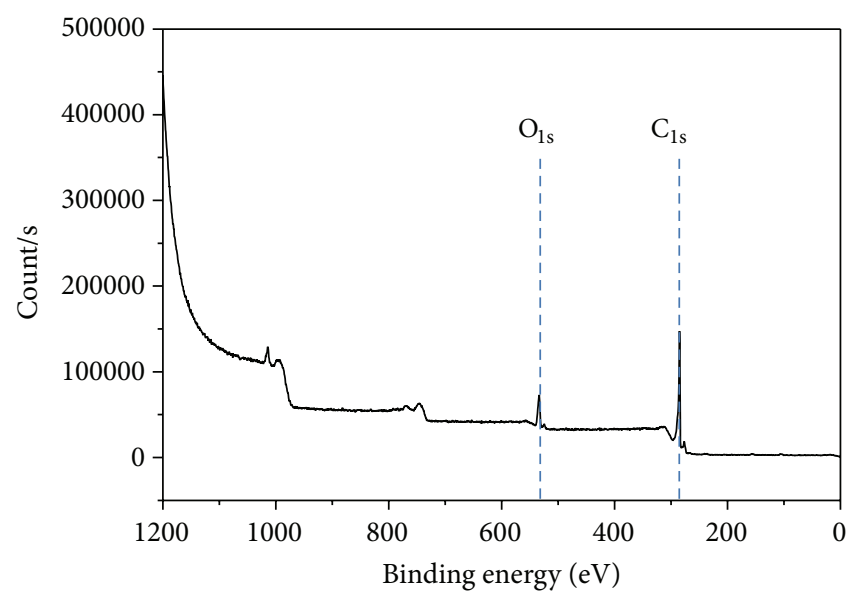

(d)

FIGURE 6: XPS survey scan spectra of the poly (ADPA)-g-MWNT (a), poly(AA)-g-MWNT (b), poly(NaSS)-g-MWNT (c), and poly(MA)-gMWNT (d). 


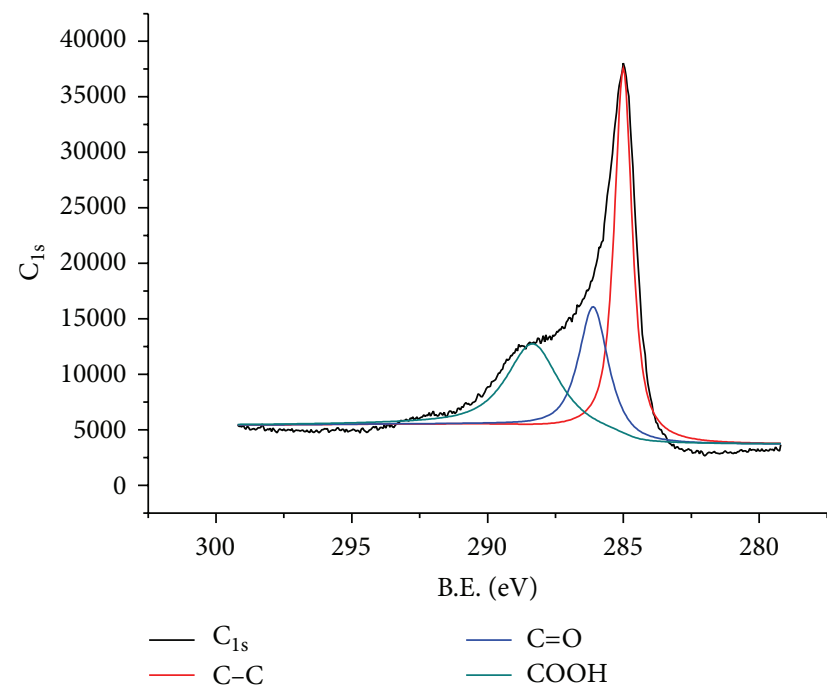

(a)

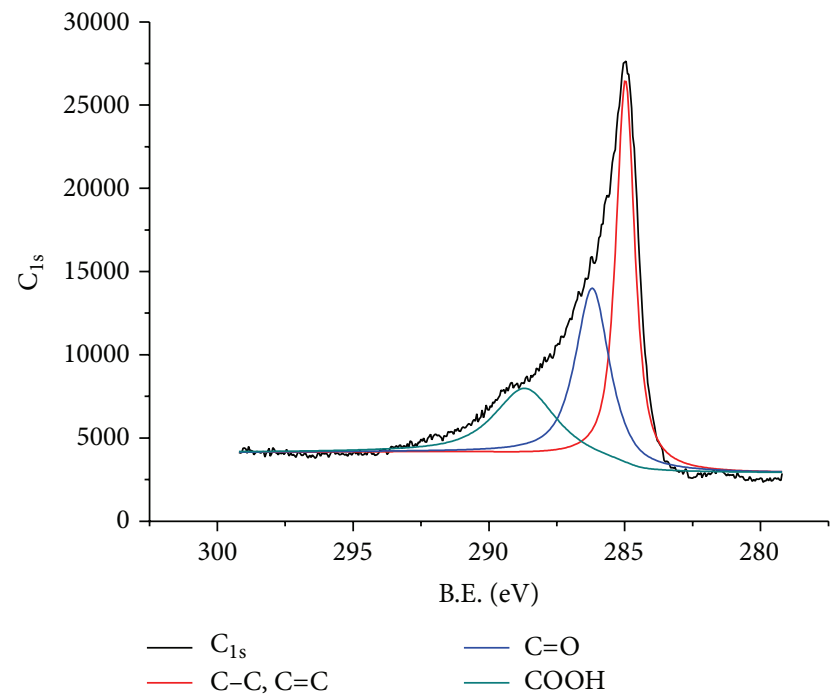

(c)

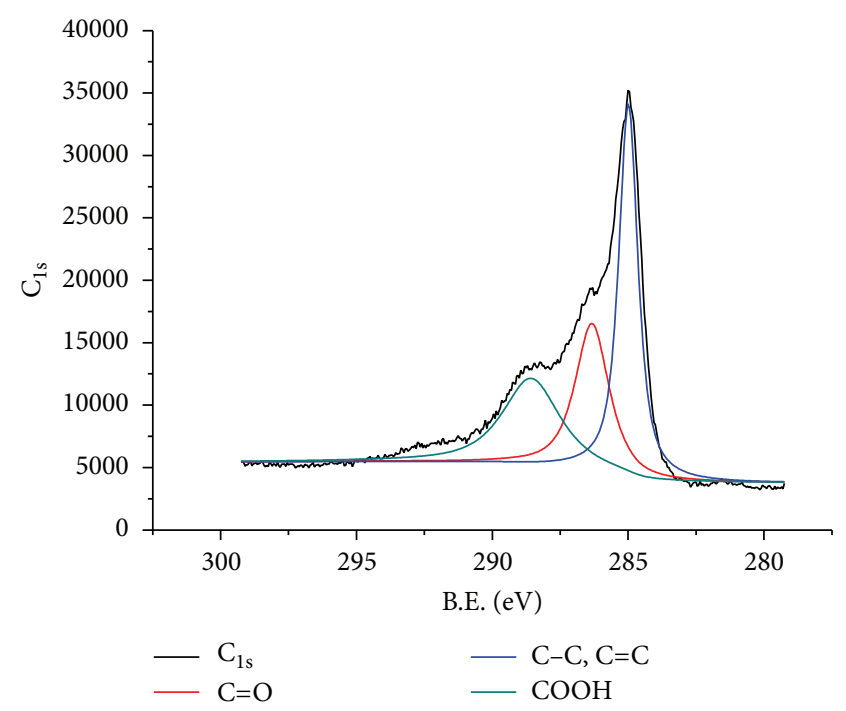

(b)

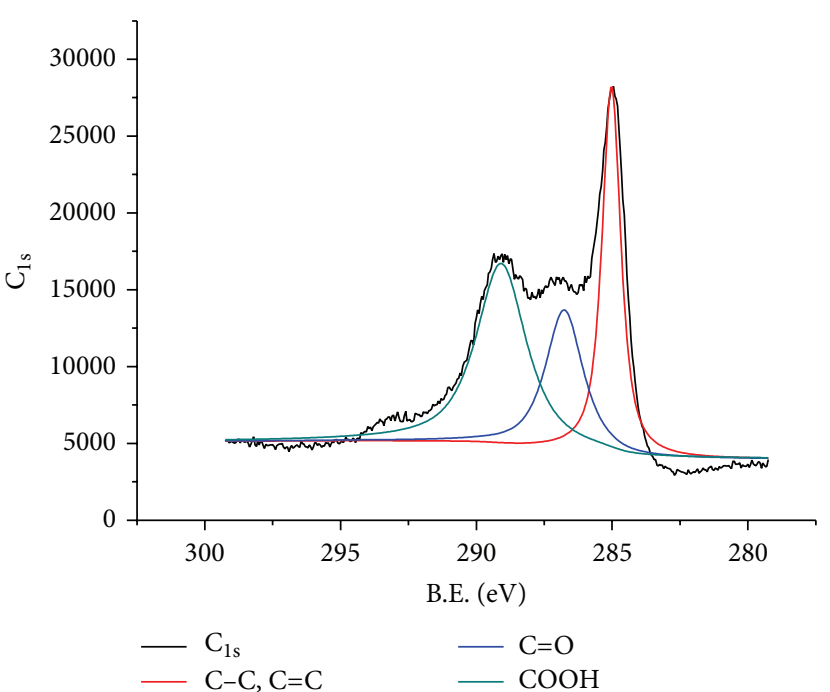

(d)

FigURE 7: High-resolution XPS spectra of the $\mathrm{C}_{1 \mathrm{~s}}$ on poly(ADPA)-g-MWNT (a), poly(AA)-g-MWNT (b), poly(NaSS)-g-MWNT (c), and poly(MA)-g-MWNT (d).

was confirmed by ${ }^{1} \mathrm{H}$ NMR (DMSO-d6), FTIR, and MS spectroscopy. ${ }^{1} \mathrm{H}$ NMR (DMSO-d6, TMS): $3.0-3.2(t, 1 \mathrm{H}$, $=\mathrm{CH}-$ ), $1.1 \sim 1.3 \mathrm{ppm}\left(\mathrm{d}, 2 \mathrm{H}, \mathrm{CH}_{2}=\right)$; $\operatorname{FTIR}(\mathrm{KBr}): 1730 \mathrm{~cm}^{-1}$ $(>\mathrm{C}=\mathrm{O}), 1000 \mathrm{~cm}^{-1}(\mathrm{P}=\mathrm{O}), 3500 \mathrm{~cm}^{-1}(-\mathrm{OH}) ; \mathrm{MS} m / z 232$.

\subsection{Radiation-Induced Graft Polymerization of Vinyl Mono-} mer onto MWNT Surface. MWNTs were purified using phosphoric acid (97\%) to remove the catalyst and noncrystallized carbon impurities. They were then used to support the grafted vinyl monomers. MWNTs (1.0 g) and GMA (1.0 g) were mixed in a $20 \mathrm{~mL}$ aqueous solution. Nitrogen was bubbled through the solution for $30 \mathrm{~min}$ to remove any residual oxygen, and the solution was irradiated by $30 \mathrm{kGy} \gamma$ rays from a Co-60 source at $1.0 \times 10^{4} \mathrm{~Gy} / \mathrm{h}$ at atmospheric pressure and ambient temperature. The resulting samples were separated by centrifuge and then dried at $50^{\circ} \mathrm{C}$ for $12 \mathrm{hrs}$.

2.4. Preparation of ECL-GCE and ECL-SPE Biosensors. MWNTs were purified using phosphoric acid (97\%) to remove the catalyst and noncrystallized carbon impurities. They were then used to support the grafted NaSS. MWNTs $(1.0 \mathrm{~g})$ and NaSS $(1.0 \mathrm{~g})$ were mixed in $20 \mathrm{~mL}$ water. Nitrogen was bubbled through the solution for $30 \mathrm{~min}$ to remove any residual oxygen, and the solution was irradiated by $30 \mathrm{kGy} \gamma$-rays from a Co-60 source at $1.0 \times 10^{4} \mathrm{~Gy} / \mathrm{h}$ at atmospheric pressure and ambient temperature. The resulting samples were separated by centrifuge and then dried at $50^{\circ} \mathrm{C}$ for $12 \mathrm{hrs}$. The other supporting materials poly(ADPA), 

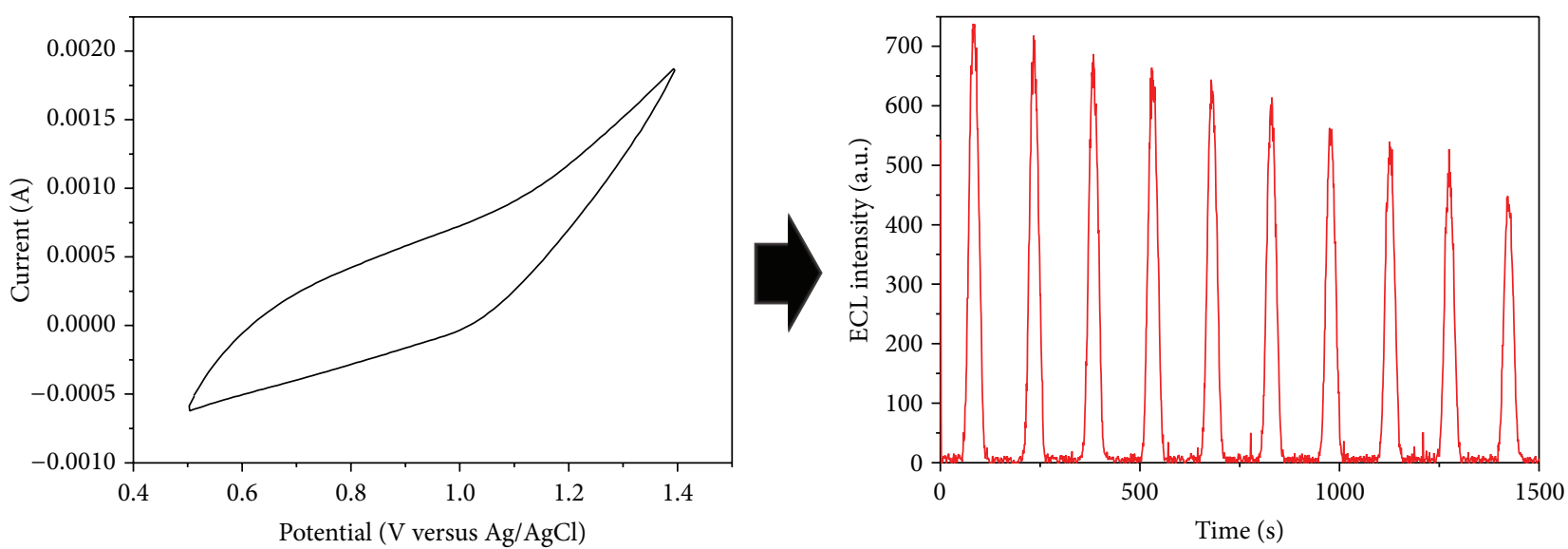

(a)
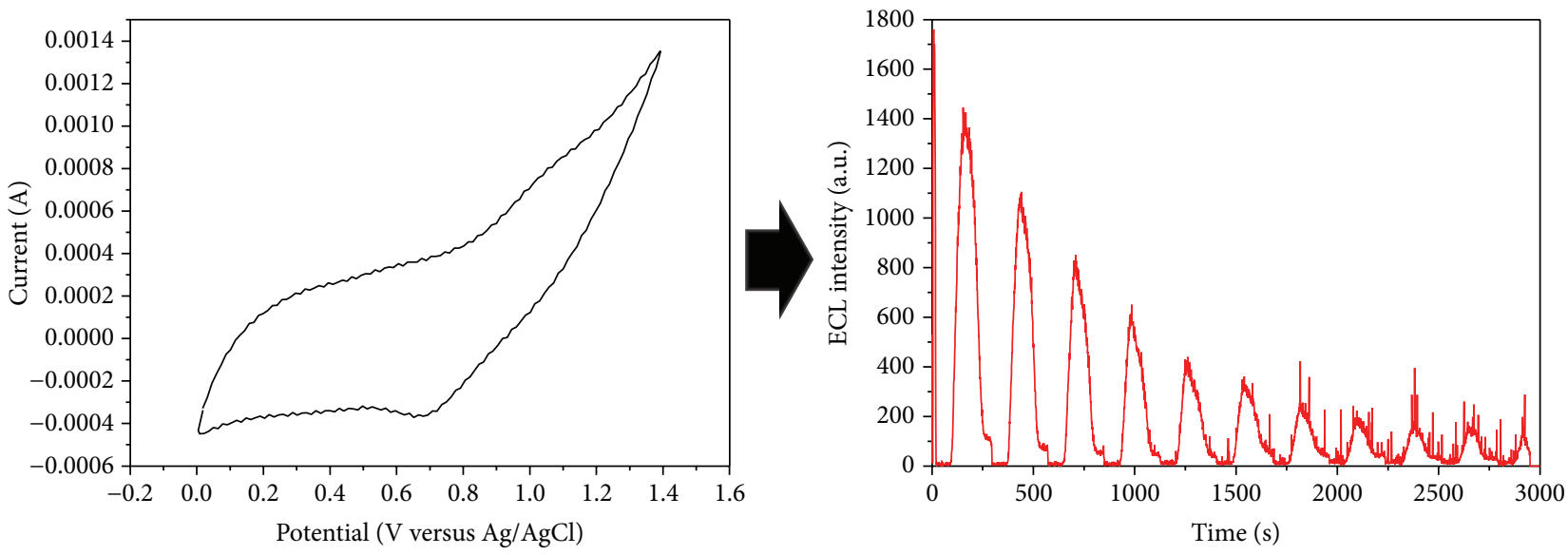

(b)

FIgURE 8: Cyclic voltammograms and ECL intensity of the ECL-GCE (a) and ECL-SPE (b) prepared by poly(ADPA)-g-MWNT in 0.1 M phosphate buffer solution $(\mathrm{pH}=7.0)$ containing $5 \mathrm{mM}$ TPA with scan rate $100 \mathrm{mV} / \mathrm{s}$.

poly(AA), and poly(MA) were also prepared by a similar method as described above.

Figure 1 outlines the preparation of the ECL-GCE and ECL-SPE biosensors based on vinyl polymer-grafted MWNT for detection of alcohol. The MWNT support ink was prepared by dispersing $3.0 \mathrm{mgL}^{-1}$ sulfonated MWNT supports and $2.0 \mathrm{mM} \mathrm{Ru}(\mathrm{bpy})_{3}{ }^{2+}$ in $5 \mathrm{wt} \%$ Nafion solution for $24 \mathrm{hrs}$ at room temperature. $10 \mu \mathrm{L}$ of this was hand cast onto a precleaned glassy carbon electrode (GCE) and homemade screen printed electrode (SPE). The thin composite film was allowed to evaporate for $60 \mathrm{~s}$ at room temperature. $10 \mathrm{mg} \mathrm{mL}^{-1} \mathrm{ADH}$ solution was then hand cast onto the $\mathrm{Ru}(\mathrm{bpy})_{3}{ }^{2+}$-immobilized MWNT support electrode. The resulting ECL biosensor was allowed to dry and was stored at $4^{\circ} \mathrm{C}$.

2.5. Instrumentation. Cyclic voltammetry (CV) was performed using a Potentiostat/Galvanostat model 283 (Ametek PAR, USA) and a conventional three-electrode system comprising a composite-coated glassy carbon (diameter, $2 \mathrm{~mm}$ ) working electrode, a platinum wire counter electrode, and an $\mathrm{Ag} / \mathrm{AgCl}$ (saturated $\mathrm{KCl}$ ) reference electrode. The screen printed electrode with $2.0 \mathrm{~mm}$ (diameter) working electrode, $\mathrm{Ag} / \mathrm{AgCl}$ inks, and carbon paste counter electrode was fabricated by a screen printer produced by Hyochang Mechanical Company (Seoul, Republic of Korea). ECL testing was conducted using an H7468-01 photomultiplier tube (PMT) system (Hamamatsu Photonics, Shizuoka, Japan). The entire ECL cell was enclosed in a light-proof dark box. The morphology of the vinyl polymer-modified MWNT supports was observed by transmission electron microscopy (TEM, Carl Zeiss, EM 912 Omega, Germany). Surface properties were characterized by FT-IR spectroscopy (PerkinElmer Life and Analytical Sciences, USA) and X-ray photoelectron spectroscopy (Thermo Fisher Scientific, MultiLab ESCA2000, USA). Thermogravimetric analysis (TGA) was conducted on a Scinco TGA S-1000 (Seoul, Republic of Korea) under $\mathrm{N}_{2}$ flow from $25^{\circ} \mathrm{C}$ to $700^{\circ} \mathrm{C}$ at $20^{\circ} \mathrm{C} / \mathrm{min}$.

\section{Results and Discussion}

3.1. Radiation-Induced Graft Polymerization of Vinyl Monomers on MWNT Surface. For MWNTs to be used 

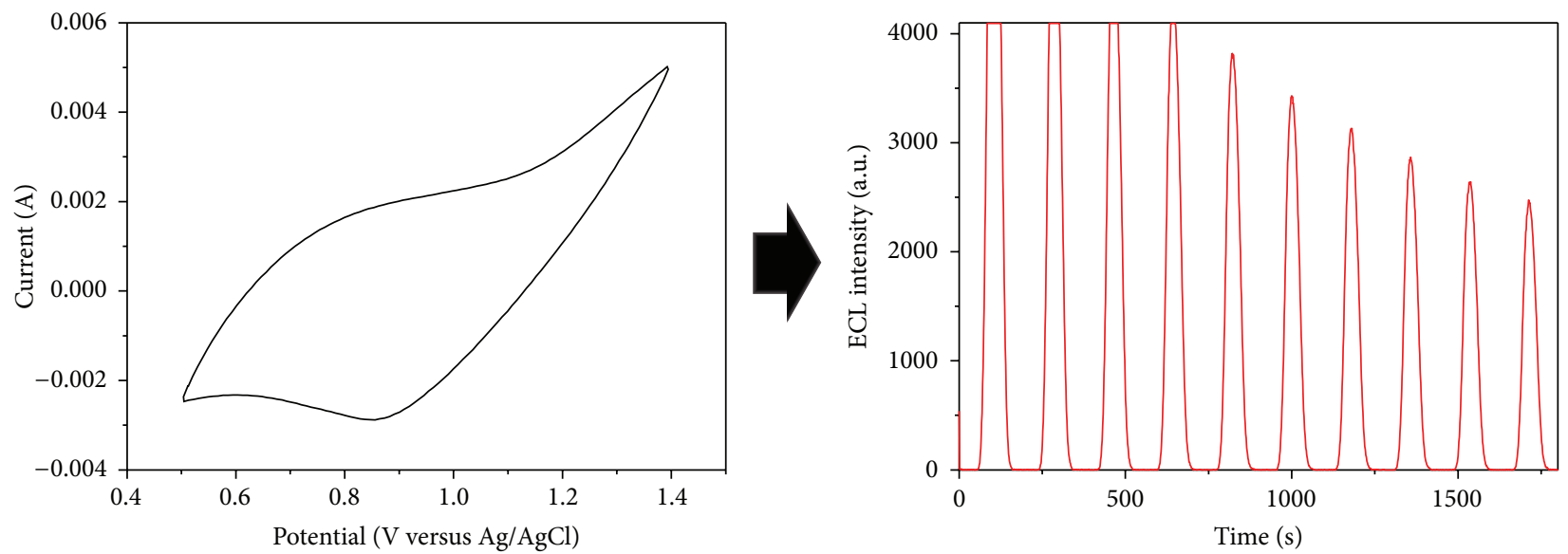

(a)
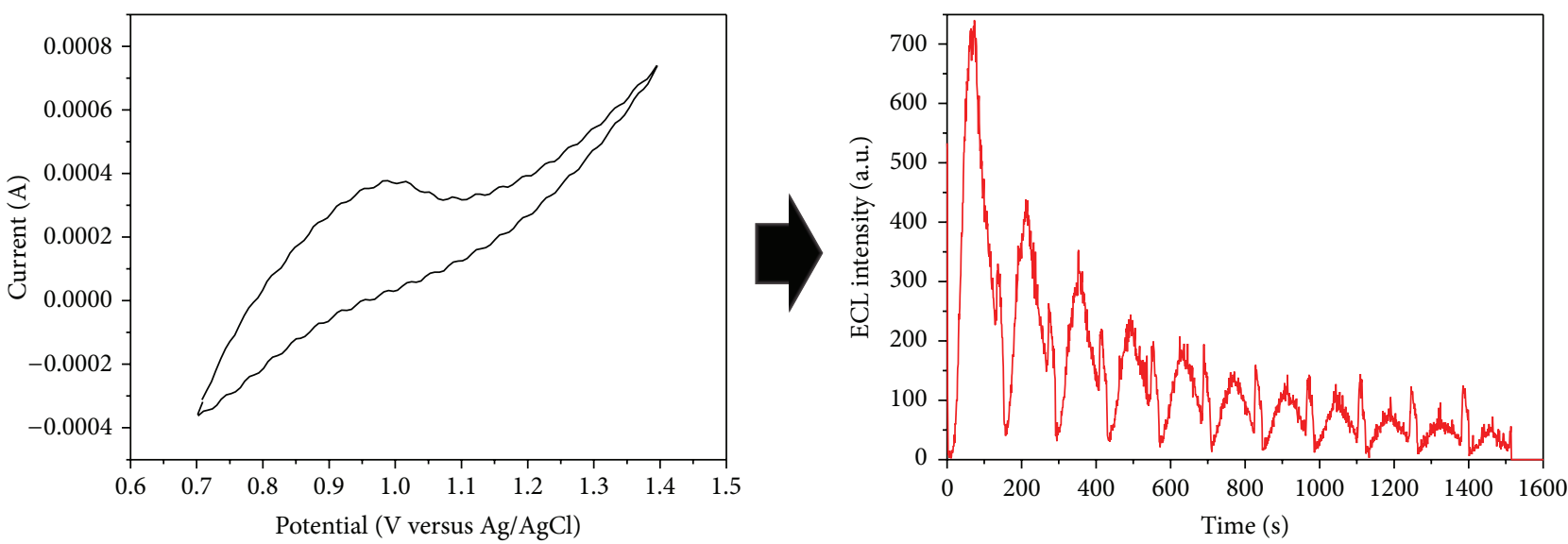

(b)

Figure 9: Cyclic voltammograms and ECL intensity of the ECL-GCE (a) and ECL-SPE (b) prepared by poly(NaSS)-g-MWNT in $0.1 \mathrm{M}$ phosphate buffer solution $(\mathrm{pH}=7.0)$ containing $5 \mathrm{mM}$ TPA with scan rate $100 \mathrm{mV} / \mathrm{s}$.

as hosts for cationic metal complexes, the introduction of anionic groups onto MWNT surfaces is very important. Anion groups can be easily introduced onto the surface of MWNTs by RIGP of vinyl monomers with anion groups in aqueous solution. The vinyl monomers ADPA, AA, NaSS, and MA were used here because they possess anion groups that can be used to immobilize ruthenium complexes. The vinyl monomers contain hydrophobic vinyl groups as well as hydrophilic anion groups, and the vinyl groups interacted with the MWNT surfaces and the aqueous mixture solution. Figure 2 shows the possible grafting mechanism of MA onto the surface of MWNTs in aqueous solution during $\gamma$-irradiation. Two active species, namely, free radicals and solvated electrons $\left(\mathrm{e}_{\mathrm{aq}}^{-}\right)$, can be obtained in aqueous solution during $\gamma$-ray irradiation as shown in the following equation [11]:

$$
\mathrm{H}_{2} \mathrm{O} \longrightarrow \mathrm{e}_{\mathrm{aq}}^{-}, \mathrm{H}^{+}, \mathrm{H}^{\bullet}, \mathrm{OH}^{\bullet}, \mathrm{H}_{2} \mathrm{O}_{2}, \mathrm{H}_{2}
$$

The hydroxyl radical $\left(\mathrm{OH}^{\circ}\right)$ can be immobilized onto the MWNT surface and this produces the trapped radicals on the surface of the MWNTs as shown in Figure 2. As a result, the trapped radicals on the MWNTs can be initiated for grafting polymerization of MA on the surface of the MWNTs as shown in Figure 2. A similar grafting process as that described above can be expected for the other vinyl monomers ADPA, AA, and NaSS.

Figure 3 shows the TEM images of the purified MWNT (a), poly(ADPA)-g-MWNT ((b), (c)), and poly(MA)-gMWNT ((d), (e), and (f)). The radical polymerization of vinyl monomers on the MWNTs during $\gamma$-irradiation led to anion groups being immobilized on the MWNTs as tubular coatings (Figure 3), which increased the diameter from $20 \mathrm{~nm}$ to $37 \mathrm{~nm}$. Overall, the anion group-modified MWNT supports were successfully prepared by one-step radiation graft polymerization.

Figure 4 shows the energy dispersive X-ray spectroscopy (EDS) data of the poly(ADPA)-g-MWNT (a), poly(AA)-gMWNT (b), poly(NaSS)-g-MWNT (c), and poly(MA)-gMWNT (d). For the poly(ADPA)-g-MWNT (Figure 4(a)), the $\mathrm{P}$ element peak appeared owing to the grafted poly(ADPA). For the poly(NaSS)-g-MWNT (Figure 4(c)), the $\mathrm{S}$ and $\mathrm{Na}$ element peaks were recorded owing to the grafted poly(NaSS). In the case of the poly(AA)-g-MWNT and poly(MA)-g-MWNT, the $\mathrm{C}$ and $\mathrm{O}$ element peaks 

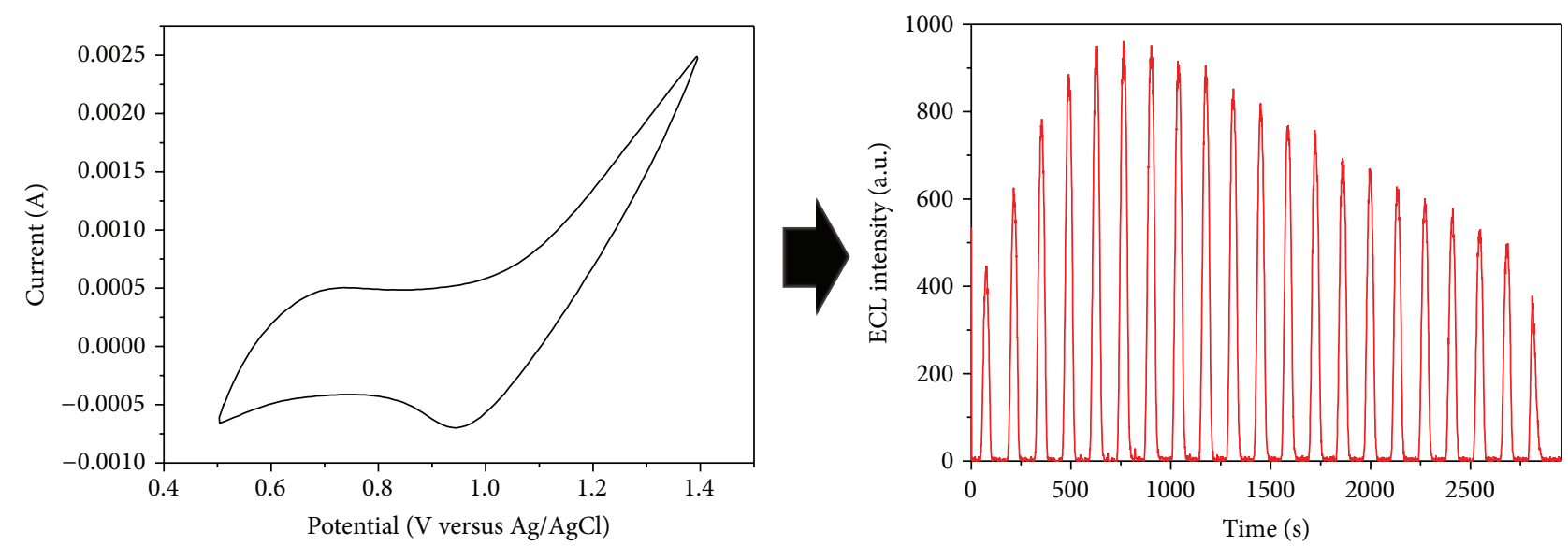

(a)
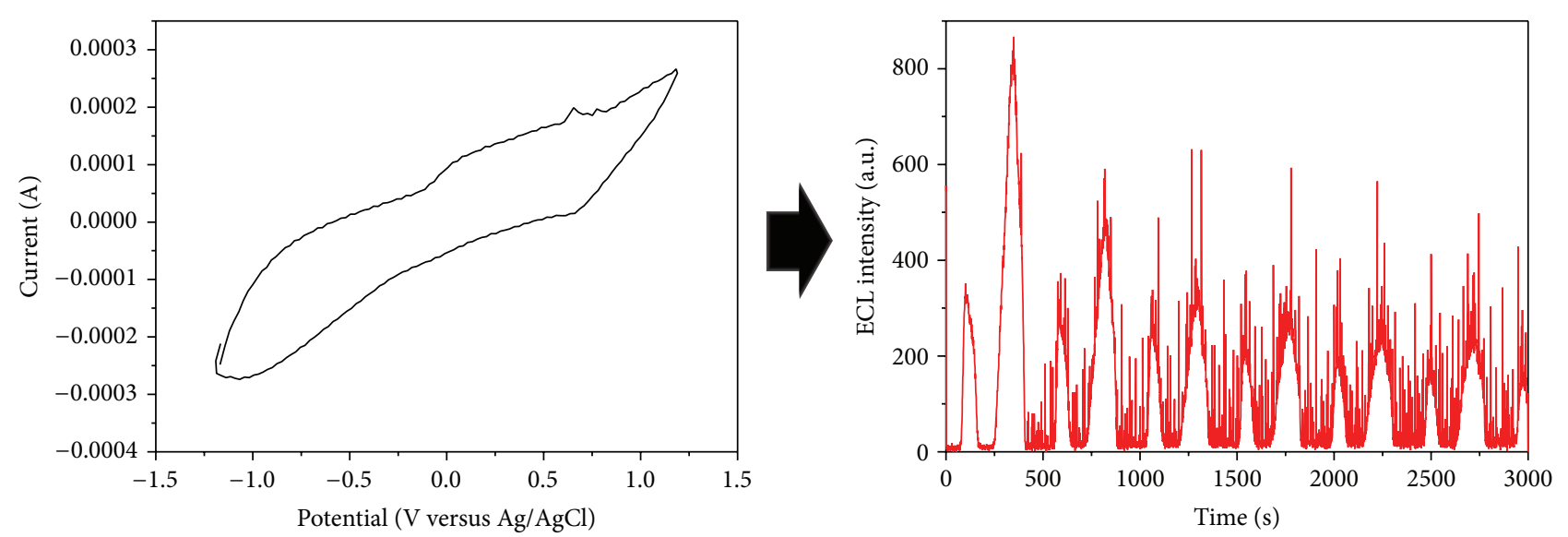

(b)

FIGURE 10: Cyclic voltammograms and ECL intensity of the ECL-GCE (a) and ECL-SPE (b) prepared by poly(MA)-g-MWNT in 0.1 M phosphate buffer solution $(\mathrm{pH}=7.0$ ) containing $5 \mathrm{mM}$ TPA with scan rate $100 \mathrm{mV} / \mathrm{s}$.

were found. From these results, it is shown that the vinyl monomers with anion groups were successfully grafted onto the surface of the MWNT by one-step radiation-induced graft polymerization.

In order to confirm the introduction of an anion group of vinyl polymer-g-MWNT, thermal analysis was performed. Figure 5 shows the TGA curves of purified MWNT (a), the poly(ADPA)-g-MWNT (b), poly(AA)-g-MWNT (c), poly(NaSS)-g-MWNT (d), and poly(MA)-g-MWNT (e). In Figure $5(\mathrm{a})$, the first weight loss from $50^{\circ} \mathrm{C}$ to $250^{\circ} \mathrm{C}$ for the purified MWNT was attributable to moisture loss because of the hydrophilic properties stemming from modification of the carboxylic acid on the MWNT surfaces. A second weight loss from the MWNT backbone appeared at $600^{\circ} \mathrm{C}$. For the poly(ADPA)-g-MWNT (Figure 5(b)), the second weight loss at $250-600^{\circ} \mathrm{C}$ occurred through the grafted poly(ADPA). These results show that graft yields were about $22.0 \%$ after RIGP of ADPA monomers. As shown in Figures 5(c), 5(d), and 5(e), the graft yields were about $25.0 \%$ after RIGP of AA, NaSS, and MA. These anion-modified MWNTs can be used as host supports in order to immobilize ruthenium complexes.

Figures 6 and 7 show the XPS survey scan spectra and high-resolution XPS spectra of the Cls and N1s of the poly(ADPA)-g-MWNT (a), poly(AA)-g-MWNT (b), poly(NaSS)-g-MWNT (c), and poly(MA)-g-MWNT (d). In the XPS survey scan spectra of poly(ADPA)-g-MWNT (Figure 6(a)), the characteristic $\mathrm{P}_{2} \mathrm{p}_{3 / 2}$ peak appeared at $134 \mathrm{eV}$ owing to diphosphoric acid on the grafted poly(ADPA) on the MWNT surface. In the XPS survey scan spectra in Figure 6(c), the characteristic $S 2 p_{3 / 2}$ peak appeared at $168 \mathrm{eV}$ owing to the grafted poly(NaSS) on the MWNT surface. In the XPS survey scan spectra of Figures 6(b) and 6(d), there is a Cls peak around $285 \mathrm{eV}$ and an O1s peak around $533 \mathrm{eV}$ due to poly(AA)-g-MWNT and poly(MA)-g-MWNT, respectively. In the high-resolution XPS spectra of Figure 6(a), a small amount of carbonyl group $(>\mathrm{C}=\mathrm{O})$ appeared at $286-287 \mathrm{eV}$ on the poly(ADPA). Grafting with vinyl monomer resulted in an additional peak at $288.7-289.5 \mathrm{eV}$ due to carbonyl groups in the polymer chains (Figures 7(a), 7(b), and 7(d)). In Figure 7(c), a small amount of carbonyl carbon is shown because carboxylic acid is produced during purification of MWNT using strong acid solution. As shown by the results, the anion group was successfully introduced to the MWNT surface by RIGP. These anion group sites could be applied as a host in order to immobilize ruthenium complexes. 


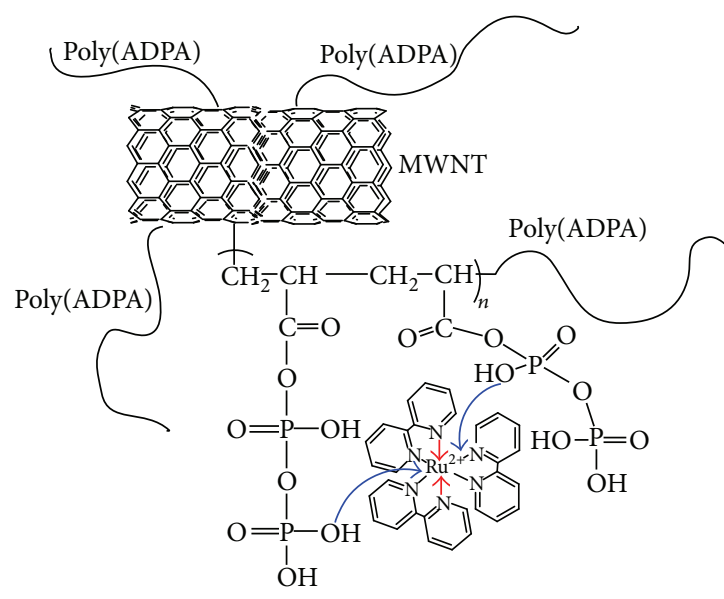

(a)

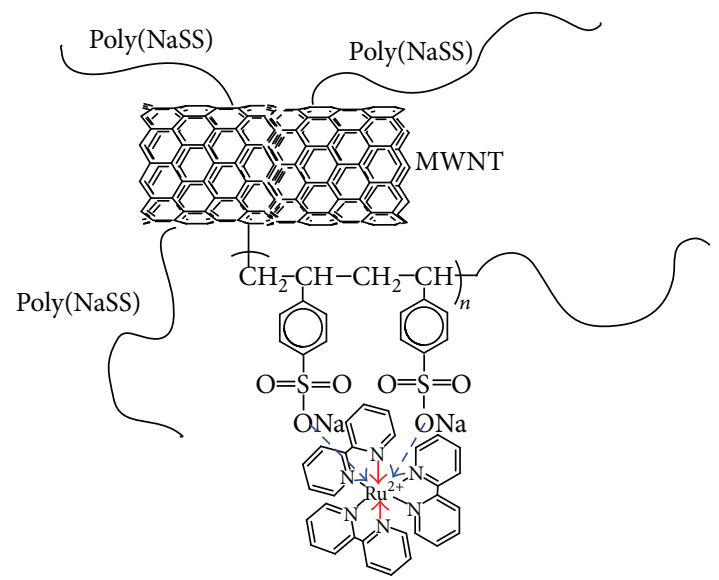

(c)

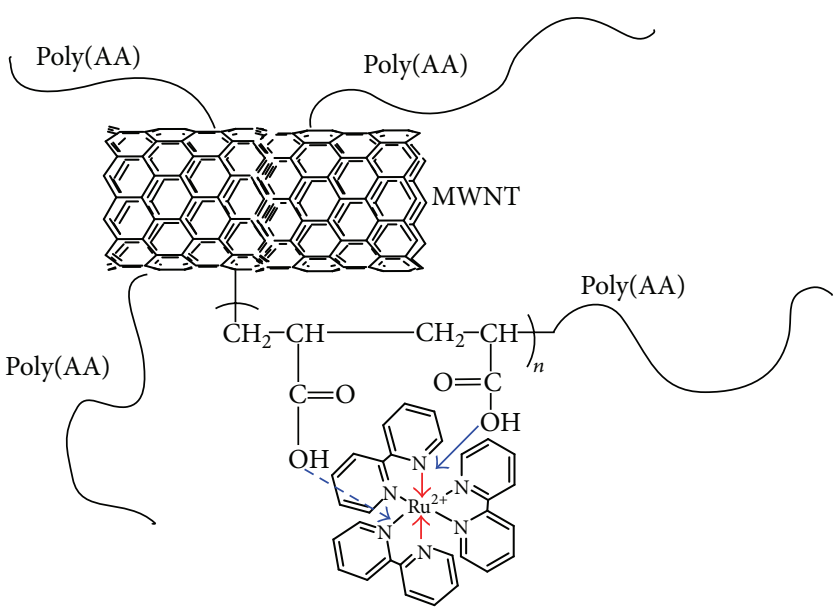

(b)

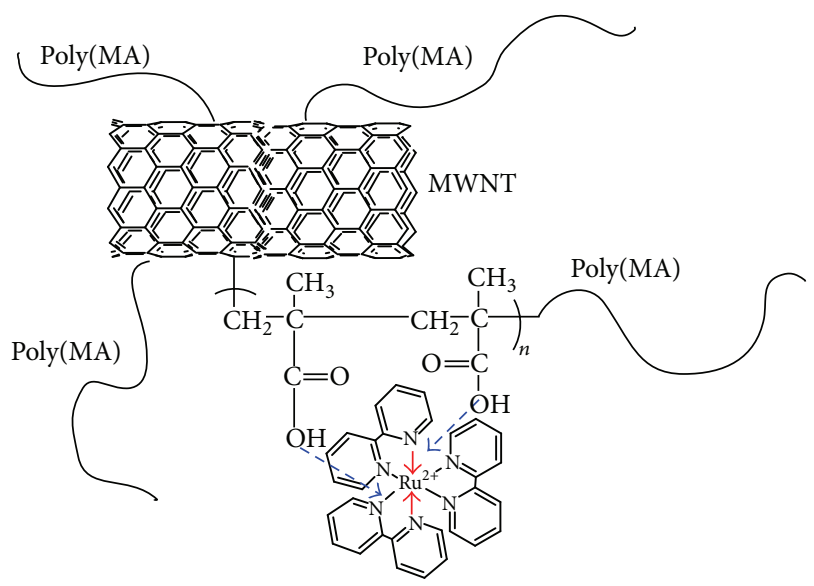

(d)

Figure 11: Introduction of $\mathrm{Ru}(\mathrm{bpy})_{3}{ }^{2+}$ complex onto poly(ADPA)-g-MWNT (a), poly(AA)-g-MWNT (b), poly(NaSS)-g-MWNT (c), and poly(MA)-g-MWNT (d).

\subsection{Application of Vinyl Polymer-Grafted MWNT to ECL} Biosensor. Cyclic voltammetry and ECL intensity measurements of ECL-GCE and ECL-SPE were carried out in PBS $(\mathrm{pH}=7.5)$ with $5.0 \mathrm{mM}$ tripropylamine (TPA) at $100 \mathrm{mVs}^{-1}$. The reaction scheme for ECL shows that the starting material, $\mathrm{Ru}(\mathrm{bpy})_{3}{ }^{2+}$, was regenerated after light emission [12]:

$$
\begin{aligned}
& \mathrm{Ru}(\text { bpy })_{3}{ }^{2+} \longrightarrow \mathrm{Ru}(\mathrm{bpy})_{3}{ }^{3+}+\mathrm{e}^{-} \\
& \mathrm{Ru}(\mathrm{bpy})_{3}{ }^{3+}+\mathrm{TPA} \longrightarrow \mathrm{Ru}(\mathrm{bpy})_{3}{ }^{2+}+\mathrm{TPA}^{\cdot} \\
& \mathrm{TPA} \longrightarrow \mathrm{TPA}^{\circ} \\
& \mathrm{Ru}(\mathrm{bpy})_{3}{ }^{3+}+\mathrm{TPA}^{\bullet} \longrightarrow\left[\mathrm{Ru}(\mathrm{bpy})_{3}{ }^{2+}\right]^{*} \\
& {\left[\mathrm{Ru}(\mathrm{bpy})_{3}{ }^{2+}\right]^{*} \longrightarrow \mathrm{Ru}(\mathrm{bpy})_{3}{ }^{2+}+\operatorname{light}(610 \mathrm{~nm}) .}
\end{aligned}
$$

Figures 7, 8, 9, and 10 show the cyclic voltammograms and ECL intensity of the ECL-GCE and ECL-SPE prepared by vinyl polymer-g-MWNT supports in $0.1 \mathrm{M}$ phosphate buffer solution $(\mathrm{pH}=7.0)$ containing $5 \mathrm{mM}$ TPA with a scan rate $100 \mathrm{mV} / \mathrm{s}$. The better cyclic voltammograms and high ECL intensity for ECL-GCE were attributed to the low conductivity of the homemade screen printed electrode. As shown by the results, the $\mathrm{Ru}(\mathrm{bpy}){ }_{3}{ }^{2+}$ was well immobilized by the anion group-modified MWNT supports. Furthermore, it was shown that ECL-GCE has an advantage over ECL-SPE in terms of ECL intensity and stability.

Figure 11 shows the introduction of $\mathrm{Ru}(\mathrm{bpy})_{3}{ }^{2+}$ complex onto the poly(ADPA)-g-MWNT (a), poly(AA)-g-MWNT (b), poly(NaSS)-g-MWNT (c), and poly(MA)-g-MWNT (d). The $\mathrm{Ru}(\mathrm{bpy})^{2+}$ complex may interact with anion groups such as diphosphoric acid, sulfonate, and carboxylic acid on the vinyl polymer-grafted MWNT.

In order to apply the biosensor, the $\mathrm{ADH}$ was immobilized onto the ECL-GCE fabricated by poly(NaSS)-g-MWNT supports, which exhibited the strongest ECL intensity, by a 

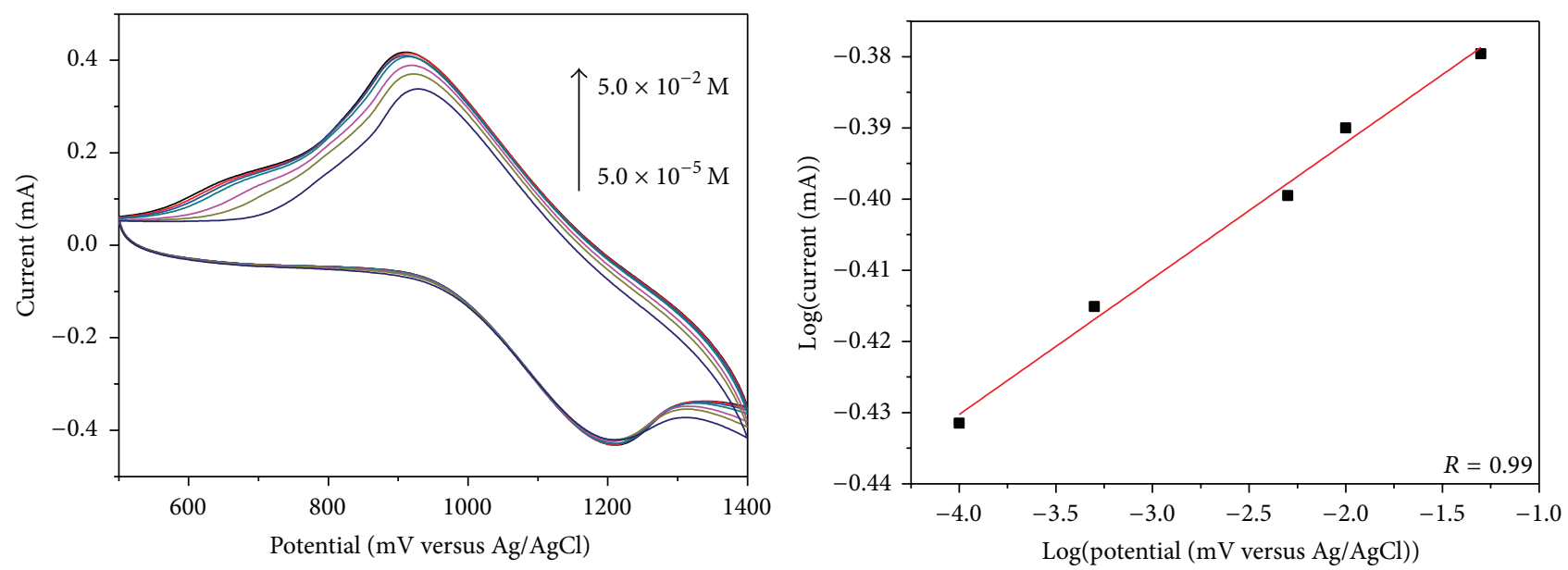

FIGURE 12: Calibration curve of the biosensor with ADH, which is prepared by poly(NaSS)-g-MWNT with Ru(bpy) ${ }_{3}^{2+}$ complex, in PBS (pH $=7.5$ ) with scan rate $100 \mathrm{mV} / \mathrm{s}$ to ethanol.
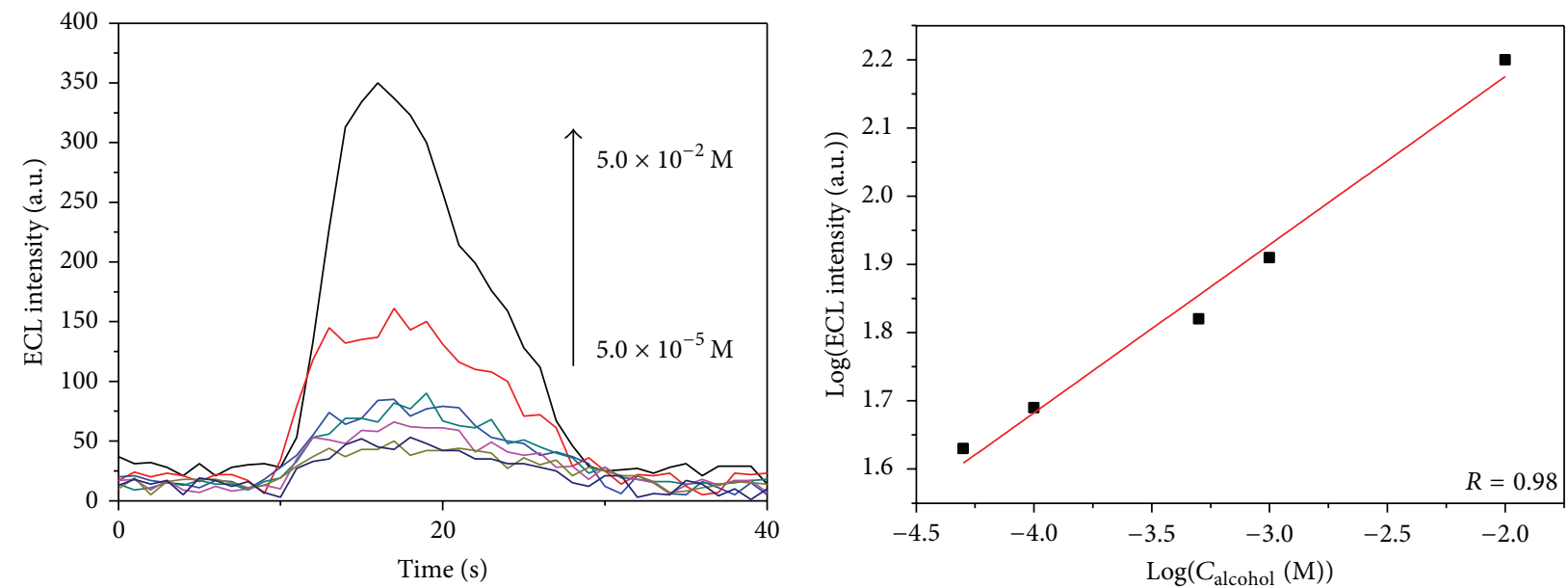

FIGURE 13: Calibration curve of biosensor with $\mathrm{ADH}$, which is prepared by poly(NaSS)-g-MWNT with $\mathrm{Ru}(\mathrm{bpy})_{3}{ }^{2+} \mathrm{complex}$, in $\mathrm{PBS}(\mathrm{pH}=$ 7.5) with scan rate $100 \mathrm{mV} / \mathrm{s}$ to ethanol.

hand casting method. Then, the electrochemical behavior of the $\mathrm{ADH}$-immobilized biosensor in $\mathrm{PBS}(\mathrm{pH}=7.5)$ with ethanol was assessed at $100 \mathrm{mVs}^{-1}$ by CV and ECL measurement. Figure 12 shows the cyclic voltammograms of the ADH-immobilized biosensor as a function of ethanol concentration. The patterns of the cyclic voltammogram did not change in accordance with ethanol concentration, while the current density at $+0.9 \mathrm{~V}$ and oxidation peaks increased slightly with increasing ethanol concentration. This suggests that the prepared ADH-immobilized biosensor could be used to detect ethanol concentration through cyclic voltammetry. The linear calibration plot of current versus logarithmic ethanol concentration for the $\mathrm{ADH}$-immobilized biosensor under optimized experimental conditions shows that the current increased with increasing ethanol concentration. The sensing range was $5.0 \times 10^{-5} \sim 5.0 \times 10^{-2} \mathrm{M}\left(R^{2}=0.99\right)$, with a detection limit of $2.9 \times 10^{-6} \mathrm{M}$ given a signal-to-noise ratio, $n$, of 3 .

Figure 13 shows the calibration curve of the biosensor with $\mathrm{ADH}$, which is prepared by poly(NaSS)-g-MWNT with
TABLE 1: Determination results of ethanol in commercial samples by using the $\mathrm{ADH}$ based biosensor.

\begin{tabular}{lcc}
\hline Sample & Nominal $(\%, v / v)$ & Biosensor $(\%, \mathrm{v} / \mathrm{v})$ \\
\hline Soju & 11 & $12.5 \pm 0.9$ \\
Beer & 5 & $6.4 \pm 0.8$ \\
\hline
\end{tabular}

$\mathrm{Ru}(\mathrm{bpy})_{3}{ }^{2+}$ complex in PBS $(\mathrm{pH}=7.5)$ with a scan rate $100 \mathrm{mV} / \mathrm{s}$ to ethanol. The calibration plot based on ECL intensity shows that ECL intensity increased with increasing ethanol concentration. The linear range of the ECL detection was $5.0 \times 10^{-5} \sim 1.0 \times 10^{-2} \mathrm{M}\left(R^{2}=0.98\right)$, with a detection limit of $5.0 \times 10^{-6} \mathrm{M}(n=3)$.

Table 1 shows the results of determinations of ethanol concentration in commercial alcohol samples using the ADH-immobilized biosensor. The ethanol concentration of the commercial alcohol determined by using the prepared biosensor was higher than the reported concentration of the 
sample. The prepared biosensor based on the vinyl polymerg-MWNT supports is suitable for use for the determination of ethanol concentrations in commercial alcohol.

\section{Conclusion}

One-step radiation-induced graft polymerization was performed using vinyl monomers in the presence of MWNTs in order to use biosensor supports. From these results we concluded the following. (1) Radiation-induced graft polymerization of the functionalized vinyl monomer could introduce very simply and easily a functional group onto the MWNT surface. (2) The prepared vinyl polymer-g-MWNT supports could be coated on the surface of GC and screen printed electrodes without any polymer binder. (3) The vinyl polymer-g-MWNT is good biosensor support.

\section{Conflict of Interests}

The authors declare that there is no conflict of interests regarding the publication of this paper.

\section{Acknowledgments}

This work was supported by the National Research Foundation of Korea Grant funded by the Korean Government (20110010853) and partially supported by the Hanna University Research Fund (2013).

\section{References}

[1] S.-H. Choi, D.-J. Chung, and H.-D. Kwen, "Fabrication of the biosensor using the vinyl polymer-grafted carbon nanotubes," in New Perspectives in Biosensors Technology and Applications, chapter 12, pp. 245-268, InTech, 2011.

[2] K.-I. Kim, B.-J. Kim, K.-C. Kim, and S.-H. Choi, "Radiolytic introduction of multiple functional groups to multiwalled carbon nanotubes and their application as biosensor supports," Journal of Applied Polymer Science, vol. 128, no. 3, pp. 22302235, 2012.

[3] Y.-J. Lee, D.-J. Chung, S.-H. Oh, and S.-H. Choi, "Introduction of bifunctional group onto MWNT by radiation-induced graft polymerization and their use as biosensor supporting materials," Journal of Nanomaterials, vol. 2012, Article ID 127613, 8 pages, 2012.

[4] D.-J. Chung, A. K. Whittaker, and S.-H. Choi, "Electrochemical DNA biosensor based on IL-modified MWNTs electrode prepared by radiation-induced graft polymerization," Journal of Applied Polymer Science, vol. 126, supplement 2, pp. E28-E33, 2012.

[5] R. D. Gerardi, N. W. Barnett, and S. W. Lewis, "Analytical applications of tris(2,2' -bipyridyl)ruthenium(III) as a chemiluminescent reagent," Analytica Chimica Acta, vol. 378, no. 1-3, pp. 1-41, 1999.

[6] Y. Tao, Z.-J. Lin, X.-M. Chen et al., "Functionalized multiwall carbon nanotubes combined with bis $\left(2,2^{\prime}\right.$-bipyridine)-5amino-1,10-phenanthroline ruthenium(II) as an electrochemiluminescence sensor," Sensors and Actuators B: Chemical, vol. 129, no. 2, pp. 758-763, 2008.
[7] S. Ye, H. Li, and W. Cao, "Electrogenerated chemiluminescence detection of adenosine based on triplex DNA biosensor," Biosensors and Bioelectronics, vol. 26, no. 5, pp. 2215-2220, 2011.

[8] D.-J. Jung, M.-H. Piao, S.-H. Oh, J.-C. Woo, and S.-H. Choi, "Fabrication of chemiluminescence sensor based on conducting polymer@SiO 2 /nafion composite film," Journal of Nanoscience and Nanotechnology, vol. 10, no. 10, pp. 6855-6858, 2010.

[9] H.-D. Kwen, S.-H. Oh, and S.-H. Choi, "Preparation and characterization of electrogenerated chemiluminescene (ECL) sensor by electrochemical grafting of 4-nitrophenyl diazonium salts onto glass carbon electrode," Journal of Nanoscience and Nanotechnology, vol. 12, no. 7, pp. 6000-6004, 2012.

[10] D.-J. Chung, K.-C. Kim, and S.-H. Choi, "Introduction of the various amine groups onto poly(glycidyl methacrylate)-gMWNTs and their application as biosensor supports," Polymer, vol. 36, no. 4, pp. 470-477, 2012.

[11] S.-H. Choi, H.-D. Kwen, and S.-H. Jung, "Radiolytic synthesis of radioisotope metallic nanoparticles," in Radiation Synthesis of Materials and Compounds, chapter 19, pp. 451-464, CRC Press, 2012.

[12] K. A. Fähnrich, M. Pravda, and G. G. Guilbault, "Recent applications of electrogenerated chemiluminescence in chemical analysis," Talanta, vol. 54, no. 4, pp. 531-559, 2001. 

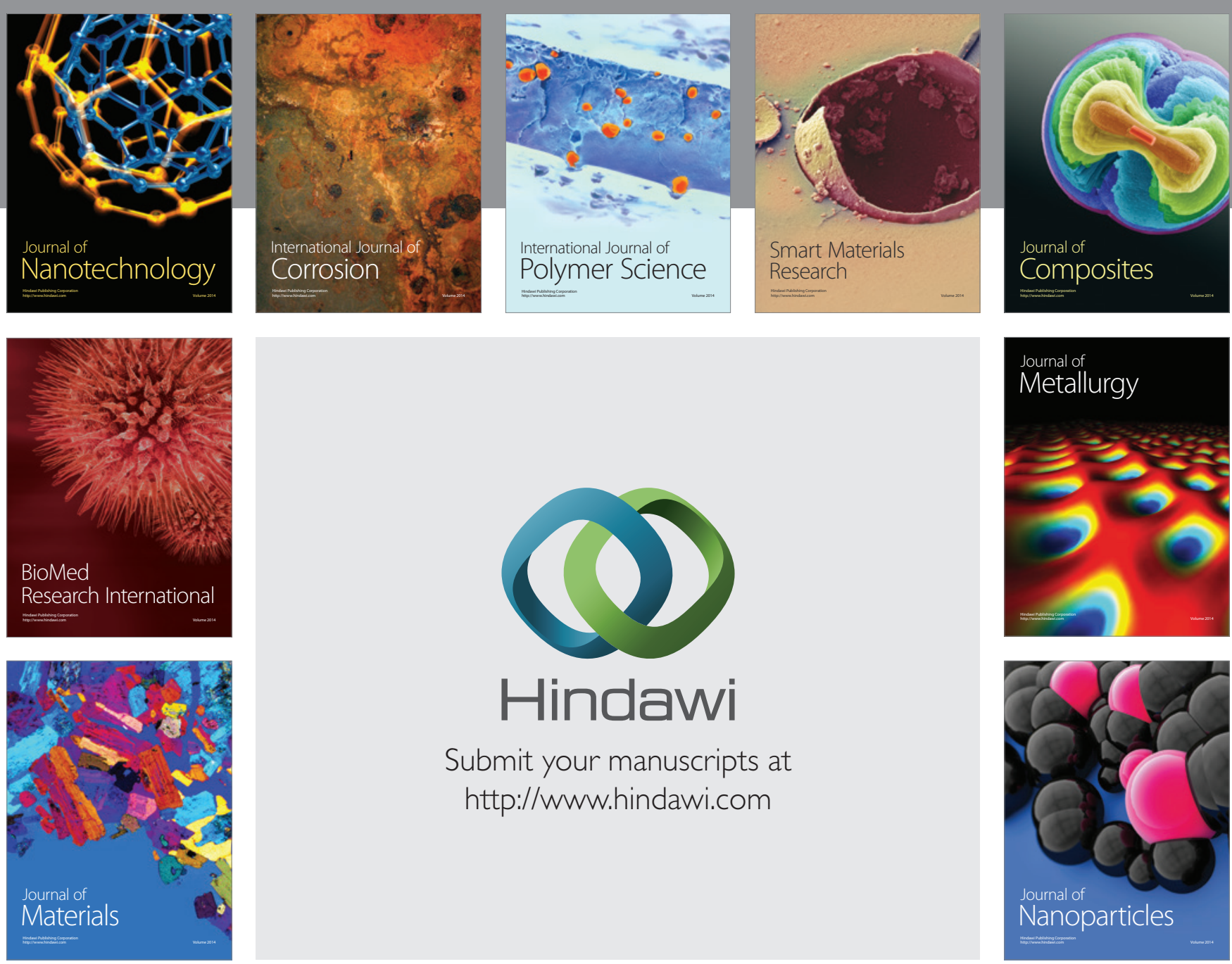

Submit your manuscripts at http://www.hindawi.com
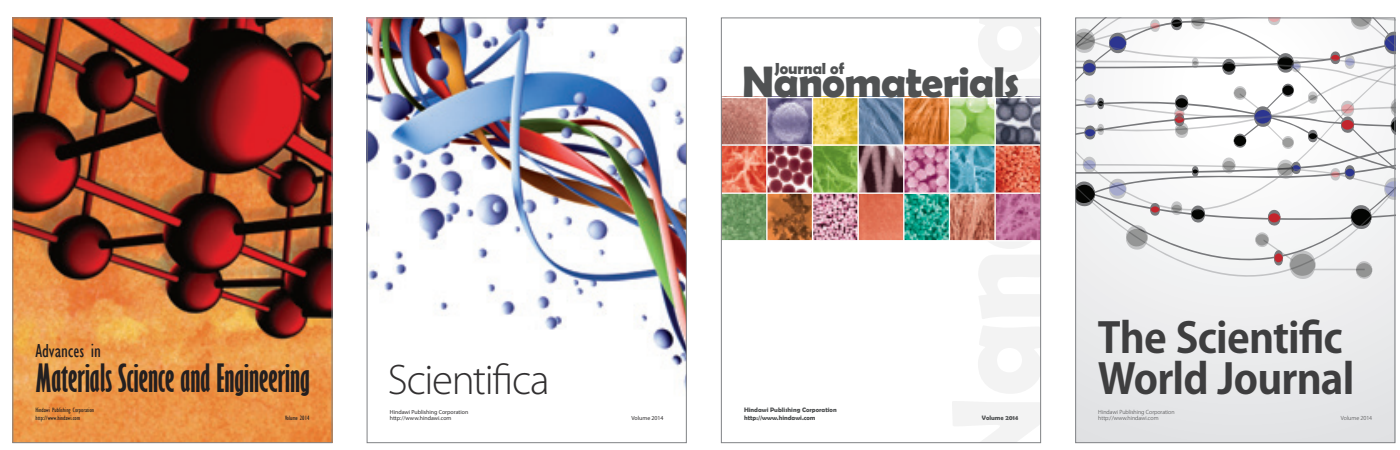

\section{The Scientific World Journal}
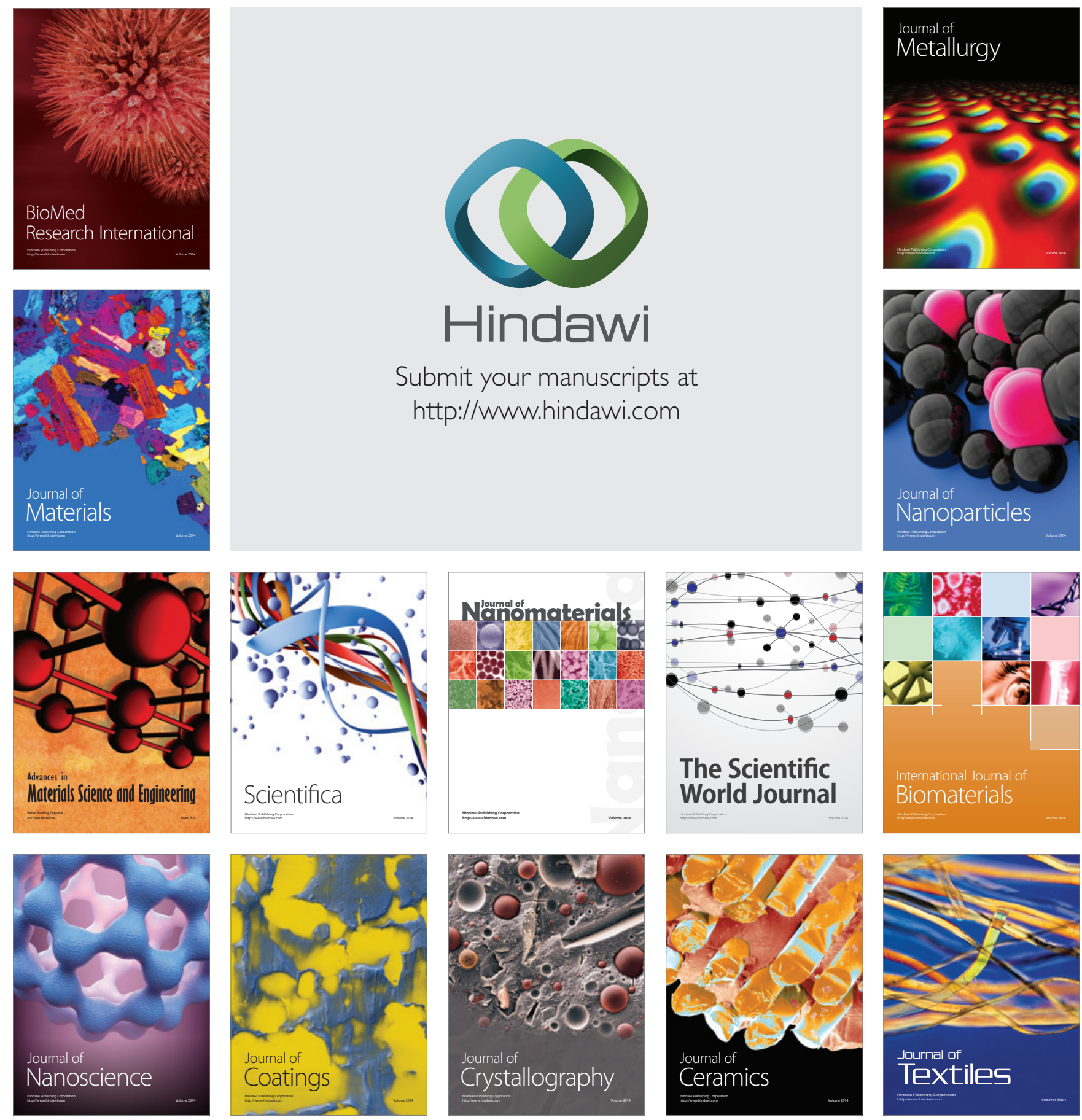